\title{
Behavioral variability is controlled by discriminative stimuli
}

\author{
JUSTIN DENNEY and ALLEN NEURINGER \\ Reed College, Portland, Oregon
}

\begin{abstract}
Previous research has demonstrated that behavioral variability can be modified by reinforcers contingent on it, but there has been no convincing evidence of discriminative stimulus control over such variability. We therefore rewarded 20 rats for variable response sequences in the presence of one stimulus and provided equal rewards independently of sequence variability in the presence of a second stimulus. We found that sequence variability was significantly higher during the first stimulus than during the second, with the greatest difference occurring immediately following onset of the stimuli. Removing the discriminative stimuli caused levels of variability to converge. These experiments provide strong evidence that behavioral variability can be controlled by discriminative stimuli, which may be important for general theories of operant behavior and their applications.
\end{abstract}

Although variability is characteristic of all physical phenomena, a particularly adaptive form may be seen in the behavior of complex organisms. We refer to variability that is shaped and influenced by consequences - - that is, operant or instrumental variability. Evidence for operant variability was obtained when rats or pigeons were reinforced for variable sequences of left (L) and right (R) responses-for example, LLRL, RRLR, and LLLL (see, e.g., Neuringer \& Huntley, 1992; Page \& Neuringer, 1985). For reinforcement, a sequence was required to differ from each of the previous three sequences. For example, given the just enumerated three sequences, if the current sequence was RLRL, it led to reinforcement, but if it was RRLRa repetition - then reinforcement was withheld. When variability was compared to that under a yoked control procedure-in which identical reinforcement was provided but without regard to sequence variability-a consistent finding was that variability was higher when reinforced than when not (see also Blough, 1966; Bryant \& Church, 1974; Holman, Goetz, \& Baer, 1977; Machado, 1989, 1992, 1993; Manabe, Staddon, \& Cleaveland, 1997; Morgan \& Neuringer, 1990; Pryor, Haag, \& O'Reilly, 1969; but for different results see Schwartz, 1982a, 1988). This sensitivity to contingencies of reinforcement is one defining characteristic of operant behavior.

Further support for the operant nature of variability came from the observation that pigeons' choices to vary or repeat followed the same matching function that describes

This research was supported in part by grants from the National Science Foundation to A.N. Portions of these data were reported by J.D. in a Reed College undergraduate thesis. We thank Gene Olson and Chris Deiss for excellent animal care and programming assistance and Armando Machado for a helpful reading of the manuscript. Correspondence concerning this article should be addressed to A. Neuringer, Psychology Department, Reed College, Portland, OR 97202 (e-mail: allen_neuringer@ reed.edu).

-Accepted by previous editor, Robert A. Rescorla simpler choices. Specifically, the probability of varying versus repeating was controlled by the probability of being reinforced for varying (Neuringer, 1992). Thus, two basic characteristics of operant responses have been found to apply to behavioral variability - that is, sensitivity to reinforcing consequences and choice that is governed by relative frequencies of reinforcement.

A third defining characteristic of operant behavior is control by discriminative stimuli. A three-term contingency characterizes the operant:

$$
\mathrm{S}^{\mathrm{D}} \rightarrow \mathrm{R} \rightarrow \mathrm{S}^{\mathrm{R}}
$$

that is, in the presence of a discriminative stimulus $\left(\mathrm{S}^{\mathrm{D}}\right)$, a response $(R)$ produces reinforcement $\left(\mathrm{S}^{\mathrm{R}}\right)$. When these relationships are in place, presenting the $S^{D}$ is found to increase the probability of response $R$, whereas in the absence of the $S^{D}$ there is little or no $R$. It is especially important to determine whether such discriminative control applies to variability, because variability is often thought to be noisesomething which experimental procedures are designed to minimize - rather than an operant dimension. Control by discriminative stimuli would help to distinguish variabilityas-operant from variability-as-noise. As will be discussed later, a clear demonstration of variability-as-operant could influence models of basic learning processes. A second reason for determining whether discriminative control applies to variability is that control by discriminative stimuli would help to rule out an alternative explanation of behavioral variability - namely, that it is elicited by decreased reinforcement frequency or other aversive aspects of the environment (see, e.g., Devenport, 1983; Schwartz, 1982b). In brief, a clear demonstration of stimulus control is necessary in order to conclude that variability is in fact an operant.

Results from two previous experiments are consistent with such discriminative stimulus control. Page and Neuringer (1985) showed that pigeons learned to vary their sequences when two response disks were green and to repeat a particular sequence when the two disks were red. Cohen, 
Neuringer, and Rhodes (1990) showed that rats learned an analogous discrimination, generating variable sequences in the presence of one stimulus and repeating a single sequence, LLRR, in the presence of a different stimulus.

However, two methodological problems with these studies prohibit us from concluding that external stimuli were, in fact, controlling the variability. First, variability was reinforced in the presence of one stimulus and repetition in the presence of another stimulus, so it is not clear whether the observed differences in variability were due to stimulus control of variation, stimulus control of repetition, or some combination of the two. The previous studies may have demonstrated discriminative stimulus control over reinforced repetition, with variability under the alternate stimulus being the default behavior. Second, neither study tested whether the external stimuli-key colors in the case of the pigeons and lights and tones in the case of the ratsactually controlled responding. An alternative interpretation is that the subjects were sensitive to the consequences of their behaviors (Jenkins, 1965). Imagine, for example, that the rats and pigeons had been deaf and blind and that they repeated a sequence as long as reinforcement was provided, but varied (including an occasional probe repetition) when reinforcers-for-repetitions were no longer forthcoming. These deaf and blind subjects might well have come to respond more variably in the presence of one stimulus than in the presence of the other. Research in our laboratory indicated that this alternative interpretation may be correct (see also Staddon \& Frank, 1974). Rats were trained under a multiple schedule of reinforcement in which variations were reinforced in the presence of one stimulus and repetitions in the presence of another. Discriminative stimulus control was the apparent result. However, when the exteroceptive stimuli were removed, leaving the contingencies otherwise intact, some of the rats continued to show appreciable separation: when the vary stimulus would have been on, the rats tended to vary more than when the repeat stimulus would have been present. It appeared that the stimuli were not, in fact, controlling performance. Thus, at present, it is unclear whether behavioral variability can be controlled by external discriminative stimuli and, consequently, whether variability is an operant.

\section{EXPERIMENT 1}

The first experiment attempted to resolve the issue of whether response variability is sensitive to control by discriminative stimuli. Rats were reinforced for variable sequences in the presence of one stimulus (vary) and given yoked reinforcement in the presence of a second stimulus (yoke). Yoked reinforcers, although contingent on responding, did not depend on sequence variability. The frequency of reinforcements in the yoke component was continually changed so that it was identical to that in the vary component. Thus, any differences observed in levels of variability would be due to reinforcement versus nonrein- forcement of variability per se. In addition, we separately analyzed the sequences occurring immediately after each component onset versus those occurring later in a component. If external stimuli were guiding variability, differences should have been seen in trials immediately following stimulus onset, when the only information available was provided by the discriminative stimuli. These procedures tested for discriminative control over behavioral variability.

\section{Method}

Subjects. Twenty female Long-Evans rats, 8 months old and experimentally naive at the beginning of the experiment, were housed in pairs and received approximately $2 \mathrm{~h}$ of access to food following experimental sessions and continuous access to water outside of the sessions. Lighting in the animal colony was on a cycle of 12 -h on and 12-h off.

Apparatus. Each of 10 Gerbrands operant chambers $(26.7 \times$ $27.9 \times 29.2 \mathrm{~cm}$ ) contained two response levers, $5.1 \mathrm{~cm}$ wide and $8.9 \mathrm{~cm}$ apart, located on either side of a food receptacle into which 45-mg Noyes food pellets could be delivered as reinforcers. Above each lever was a white light. (Three pigeon keys and a dipper on the opposite wall were not used in the present experiments.) An overhead light could illuminate the chamber, and a speaker could provide auditory stimuli. Each chamber was contained in a light- and soundattenuating box and controlled by a Macintosh computer.

Procedure. The subjects were trained to press each of the two levers by reinforcing any leverpress. After all subjects were responding consistently, a switch program alternatively activated and deactivated left and right levers such that five reinforcements were obtained from the left, then five from the right, and so forth. This schedule was maintained until all rats were responding consistently to both levers, which took no more than three or four sessions. A trials procedure was then instituted in which four consecutive responses constituted one trial. Each of the first three responses caused the light above the activated lever to be darkened for $0.1 \mathrm{sec}$; the fourth response caused the trial to terminate with food or not, as will be described below. Following each trial was a 2 -sec intertrial time, during which the levers were inactivated, responses did not count toward the sequence requirement, the two lever lights were darkened, and the chamber was quiet.

Stimuli cuing the vary component, in which sequence variations were reinforced, were intermixed with stimuli cuing the yoke component, in which reinforcement was provided probabilistically and independently of sequence variations. This intermixing of vary and yoke stimuli and contingencies is technically referred to as a twocomponent multiple schedule of reinforcement. Each of the components will be described separately.

Vary components. Infrequently occurring sequences were required for reinforcement in the vary component. Given that a trial consisted of four responses across left and right levers, there were 16 different possible sequences-for example, LLLL, LLLR, LLRL . . . RRRR. A sequence was followed by reinforcement only if its weighted relative frequency was less than a threshold value. The relative frequency of a sequence was defined as the number of times it had occurred (to be referred to as its count), divided by the sum of occurrences of all 16 sequences - that is, total trials. In order to weight recent sequences more than past sequences, following each reinforced trial, the counts of each of the 16 sequences were multiplied by a weighting coefficient $(w=.95)$. This multiplication resulted in an exponentiaily decreasing contribution of instant sequences as a session proceeded, such that the contribution of a current trial was twice as much as a contribution of a sequence recorded 14 reinforcements earlier. The weighted frequencies were used to calculate whether a particular sequence had occurred less frequently than 
Table 1

Application of Weighting Coefficient

\begin{tabular}{|c|c|c|c|c|c|c|c|c|c|c|c|}
\hline \multirow[b]{3}{*}{ Trial } & \multirow[b]{3}{*}{ Sequence } & \multicolumn{8}{|c|}{ Sequence } & \multirow[b]{3}{*}{$\begin{array}{l}\text { Weighted } \\
\text { Sum }\end{array}$} & \multirow[b]{3}{*}{$\begin{array}{l}\text { Reinforcement } \\
\left(S^{R}\right) \text { Received? }\end{array}$} \\
\hline & & \multicolumn{2}{|c|}{ LL } & \multicolumn{2}{|c|}{ LR } & \multicolumn{2}{|c|}{ RL } & \multicolumn{2}{|c|}{ RR } & & \\
\hline & & $\begin{array}{l}\text { Weighted } \\
\text { Frequency }\end{array}$ & $\begin{array}{c}\text { Weighted } \\
\text { Relative } \\
\text { Frequency }\end{array}$ & $\begin{array}{l}\text { Weighted } \\
\text { Frequency }\end{array}$ & $\begin{array}{l}\text { Weighted } \\
\text { Relative } \\
\text { Frequency }\end{array}$ & $\begin{array}{l}\text { Weighted } \\
\text { Frequency }\end{array}$ & $\begin{array}{l}\text { Weighted } \\
\text { Relative } \\
\text { Frequency }\end{array}$ & $\begin{array}{l}\text { Weighted } \\
\text { Frequency }\end{array}$ & $\begin{array}{l}\text { Weighted } \\
\text { Relative } \\
\text { Frequency }\end{array}$ & & \\
\hline Initial & & 1.0 & .25 & 1.0 & .25 & 1.0 & .25 & 1.0 & .25 & 4.00 & \\
\hline 1 & LL & 1.9 & .40 & 0.95 & .20 & 0.95 & .20 & 0.95 & .20 & 4.75 & Yes \\
\hline 2 & $\mathrm{LL}$ & 2.9 & .50 & 0.95 & .17 & 0.95 & .17 & 0.95 & .17 & 5.75 & No \\
\hline 3 & LL & 3.9 & .58 & 0.95 & .14 & 0.95 & .14 & 0.95 & .14 & 6.75 & No \\
\hline 4 & LR & 3.71 & .50 & 1.85 & .25 & 0.90 & .12 & 0.90 & .12 & 7.36 & Yes \\
\hline 5 & RR & 3.52 & .44 & 1.76 & .22 & 0.86 & .11 & 1.81 & .23 & 7.94 & Yes \\
\hline
\end{tabular}

Note-L, left; R, right. The weighted sum equals the sum of the weighted frequencies. The weighted relative frequency was calculated by dividing the weighted frequency by the weighted sum. The weighting coefficient $(.95)$ was applied only if a reinforcement $\left(\mathrm{S}^{\mathrm{R}}\right)$ was received, as shown in the far right column.

specified by the threshold. If, for example, an LLLR sequence had just been emitted, its weighted frequency was divided by the sum of the weighted frequencies of all 16 sequences. A reinforcer was provided only if the resulting fraction was less than or equal to the threshold value. The threshold value was eventually set at .09 (see below), indicating that only those sequences occurring less than or equal to $9 \%$ of the time were reinforced.

Table 1 shows a simplified version of calculations to demonstrate the vary contingencies. For ease of explanation, assume that each trial consists of only two responses (not the four which were actually used in the experiment)-namely, LL, LR, RL, or RR. For this example, assume that the threshold is set at .33 and the weighting coefficient at .95 . Only those sequences whose weighted relative frequencies are less than .33 will be reinforced and, following each reinforcement, all counts will be multiplied by $w=.95$. For this example, we assume that each sequence had occurred once (without reinforcement) prior to the beginning of the experiment, with initial weighted relative frequencies therefore all equal to .25 . An LL sequence was emitted in the first trial, resulting in reinforcement. The weighted count of LL becomes 1.9 , or $[(1+1)] * .95=1.9$. The weighted sum becomes 4.75 , or $[(4+1) * .95]=4.75$. Therefore the weighted relative frequency of $L L$ becomes $1.9 / 4.75=.40$. Another LL sequence is emitted in Trial 2 . Because the weighted relative frequency of the LL sequence is now higher than the .33 threshold, no reinforcement is provided, and the weighting coefficient is not applied. The numerator of LL is incremented by 1 , the sum is incremented by 1 , and the resulting weighted relative frequencies are as shown in the table across the Trial 2 line $(.50, .17, .17$, and .17 for $L L, L R, R L$, and $R R$, respectively). Another LL sequence is emitted in Trial 3, resulting again in no reinforcement, followed by $L R$ in Trial 4. Because the weighted relative frequency of LR equaled 14 at the beginning of the fourth trial, reinforcement is provided, and the weighting coefficient is applied.

Calculations of sequence frequencies were based exclusively on responses during the vary component - that is, when the vary stimuli were on. At the end of each session, the weighted frequencies were recorded for initialization of the weighted frequency array at the beginning of the next session. The weighting coefficient was applied only after reinforcement (rather than after every trial) in order to discourage such strategies as repeating a particular sequence and then switching to any other sequence. Stated simply, sequences were reinforced only if they occurred infrequently relative to all other sequences in the recent past.

Yoke components. During the yoke component, reinforcement was provided probabilistically. Separately, for each subject, the probability of reinforcement was yoked to the percentage of reinforcement that subject had received during the vary components of the previous session. For example, if during the previous session, $42 \%$ of all sequences in the vary component had been reinforced, then, during the yoke component of the current session, the probability of any sequence being reinforced-variable or not-was .42. More precisely, two different probabilities were used to govern reinforcement; one applied during initial trials - defined as the first trial following onset of a yoke or vary component - and the other probability governing reinforcements during later trials in a yoke component. Reinforcement probability for the initial trials equaled that obtained in the initial trials of the previous day's vary components. Reinforcement probability for subsequent yoke trials equaled that of the previous day's later vary trials, calculated by averaging all postinitial trials. These probabilities were separately programmed so that discriminations could not be based on different reinforcement distributions within the two components, as indicated in the introduction.

Multiple schedule conditions. Following each reinforcement, there was an equal probability $(p=.5)$ of the next component being vary or yoke. A component was maintained until a reinforcer had been received. Thus, the length of a given component depended on performance in vary and on a probability generator in yoke. As will be seen, the average length of each component (prior to the next query of the component probability generator) was approximately two trials. Terminating each component was the $2-\mathrm{sec}$ intertrial period of darkness and silence described above. This procedure was used in order to generate high variability in the vary component-if not, reinforcers would not be obtained-and to maximize likelihood of stimulus control by eliminating contextual information other than the discriminative stimuli, while frequently switching between the components. For half of the rats, the vary component was signaled by houselight illumination and the absence of a tone, and the yoke component was signaled by the continuous presence of a $6000-\mathrm{Hz}$ tone and the absence of houselight. Thus light-on/tone-off was the cue to vary and light-off/tone-on was the cue for the yoke component. For the remaining 10 rats, these stimuli were reversed - that is, lightoff/tone-on serving as the vary cue and light-on/tone-off as the yoke cue. For a given subject, the same stimulus conditions were continued throughout training.

Over the first 18 sessions, the threshold requirement in vary was systematically decreased from a value of .9 to .1 , so that, at the end of this period, a particular sequence was reinforced only if its weighted relative frequency was less than .1. After 30 sessions, many of the subjects were responding variably in the yoke component as well as in vary. Therefore, the probability of switching into the vary component following a reinforcement was temporarily decreased from .5 to 3 for all but three subjects, who had been demonstrating good stimulus control. Following Session 40 , the probability of entering the vary and yoke components was returned to .5 , and this value was 

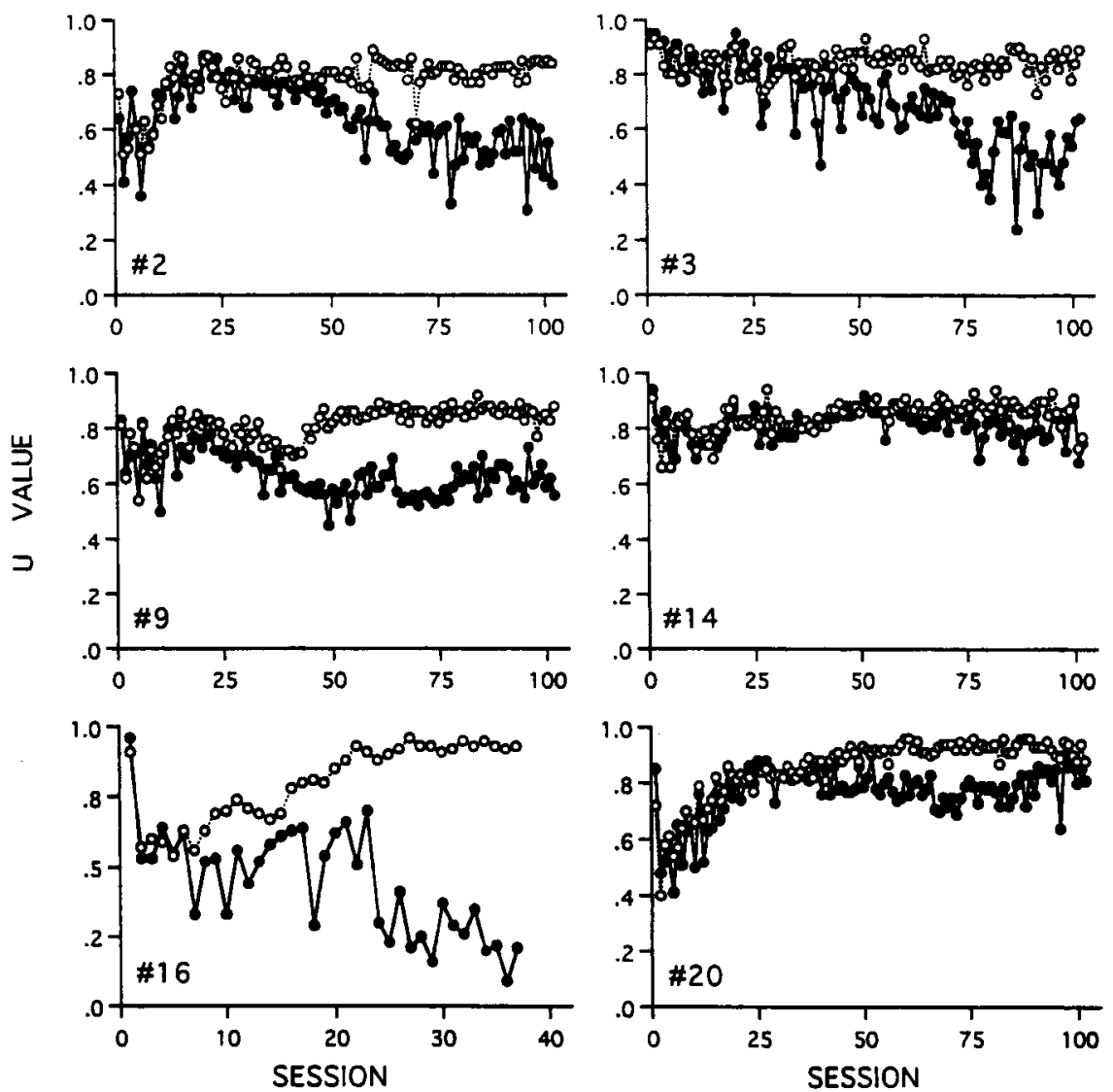

Figure 1. $U$ values, a measure of sequence variability, in the vary (open circles) and yoke (filled circles) components during each session of Experiment 1. High $U$ values indicate relatively high variability. The 6 subjects shown were chosen to represent performances across the 20 subjects.

maintained throughout the remainder of the experiment. At approximately the same time, the threshold requirement in the vary component was decreased to .09 , and this value was also maintained throughout the remaining sessions. Because 6 of the subjects quickly demonstrated stimulus control, they received training for as few as 37 sessions, but the other 14 subjects continued for approximately 100 sessions. All sessions were $60 \mathrm{~min}$ in duration.

Measures The two main dependent variables were $U$ value and percent vary.

$U$ value, a measure of sequence uncertainty or normalized entropy, is defined as

$$
-\sum_{i=1}^{16}\left[\mathrm{RF}_{i} * \log _{2}\left(\mathrm{RF}_{i}\right)\right] / \log _{2}(16),
$$

where $R F_{i}$ refers to the relative frequency of occurrence of each of the 16 possible sequences. (Note that these frequencies refer to actual occurrences and are not the weighted frequencies used in the vary contingency described above.) A high $U$ value ( 1.0 being maximum) indicates that each of the 16 possible sequences occurred with approximately equal frequency. Lower $U$ values $(0$ being the minimum) indicates that one or more sequences were highly likely, whereas others tended not to occur. $U$ values were computed separately for vary and yoke components at the end of each session.

Percent vary was calculated separately for each component by dividing the number of trials that satisfied the vary contingency by the total trials per component in a session. Although reinforcement did not depend on variability in the yoke component, percent vary was measured in yoke as well as in vary. $U$ value and percent vary statistics measure different aspects of variability. The former evaluates distributions of sequence frequencies over a complete session, yielding an index of molar variability. Higher $U$ values correspond to flatter distributions. Percent vary measures shorter term variability by assessing whether sequences were emitted infrequently relative to their decreasingly weighted past. Together, the two statistics measure different (but not orthogonal) attributes of variability.

Statistical analyses were performed on $U$ value and percent vary measures, with initial trials in a component separated from the later trials, as described above. For each subject, arithmetic averages were calculated based on the final 300 trials in the experiment ( 300 initial trials and 300 later trials), and these were then used to perform analysis of variance (ANOVA) comparisons. The three main factors were contingency (vary vs. yoke), position in the component (initial vs. later trials), and the between-subjects variable stimulus condition (whether light-on/tone-off indicated vary or yoke). Since performances under the two stimulus conditions did not differ in any important ways - showing that the effects obtained were not due to the particular stimuli assigned to vary and yoke components--these groups were collapsed in order to simplify the presentation of the results.

\section{Results}

Figure 1 shows acquisition functions for 6 subjects, 4 of these representative of the group (2. 3, 9, and 20), 1 show- 


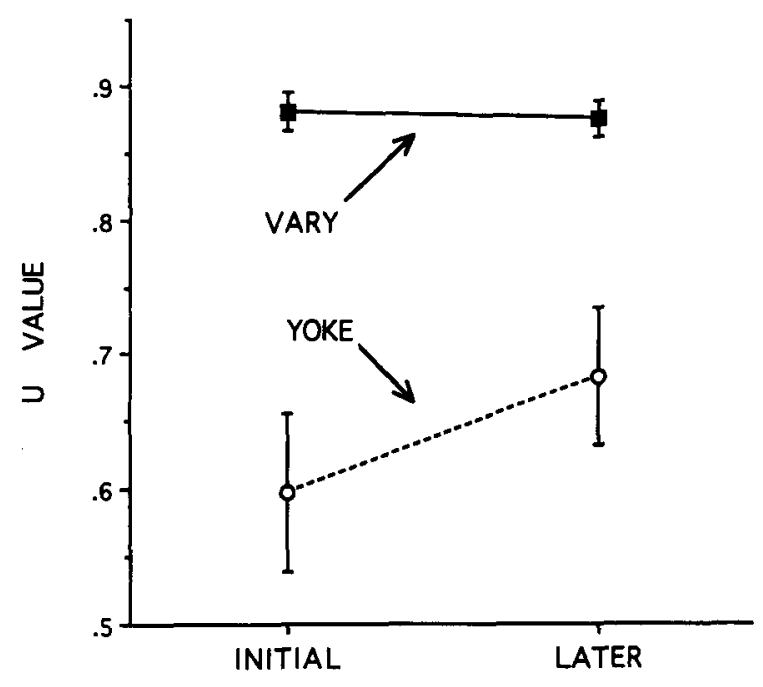

Figure 2. Average $U$ values under vary and yoke stimulus conditions in Experiment 1 and divided into initial trials-the first trial following initiation of a component-and later trials in the component. Averages across the 20 rats represent the final 300 responses in each condition. Error bars show standard deviations.

ing the smallest difference between vary and yoke (14), and 1 showing very rapid acquisition (16). Shown are the $U$ values from vary and yoke components during each session of the experiment. All subjects responded variably during the vary component, as required by the schedule contingencies. Because of the logic of the experimental design, reinforcement did not depend on any particular level of variability during the yoke component and, whereas variability decreased quickly in yoke for some subjects (e.g., 16), it remained relatively high for others (e.g., 14). By the end of the experiment, for almost all subjects, variability was consistently higher in vary than in yoke.

Over the final 300 trials, $U$ values were significantly higher in the vary component (arithmetic mean for all subjects $U=.879)$ than they were in yoke $[U=.640 ; F(1,18)=$ $22.75, p<.0005]$. The contingency (vary vs. yoke) by position (initial vs. later trials) interaction was also significant $[F(1,18)=14.16, p<.002]$. Analyses of simple effects showed that, in the vary component, initial trial versus later trial $U$ values did not differ (.883 in initial trials vs. .875 in later trials), but in yoke, $U$ values increased significantly during the later trials $[.597$ vs. $.683 ; F(1,18)=10.68$, $p<.005]$. Thus, as shown by Figure 2 , variability was higher in the vary component than in yoke, with the difference decreasing when the initial trial did not terminate with reinforcement.

A similar pattern of results was seen for the percent vary statistic, shown in Figure 3. The percentage of sequences meeting the variability contingencies was significantly higher in the vary component $(49.6 \%)$ than in yoke [ $34.6 \%$; $F(1,18)=30.48, p<.0001]$. Again there was a significant contingency $\times$ position effect $[F(1,18)=29.72, p<.0001]$. Simple effects analyses showed that variability was higher in the first trial of the component than it was later [51.4\% vs. $47.8 \% ; F(1,18)=4.63, p<.05]$, whereas the opposite was true for the yoke component, variability being lower in initial trials than in later trials $[30.3 \%$ vs. $39.0 \% ; F(1,18)=$ $12.75, p<.005]$. Thus, stimulus control was demonstrated by both $U$-value and percent vary statistics, with the greatest difference in levels of variability seen immediately following onset of the discriminative stimuli.

\section{EXPERIMENT 2}

Experiment 2 compared levels of sequence variability when discriminative stimuli were present during one session, absent during a second session, and again present during the third session.

\section{Method}

Subjects and Apparatus. The subjects and apparatus were the same as those in Experiment 1.

Procedure. This experiment took place during three sessions that immediately followed Experiment 1 . During Sessions 1 and 3, the procedure was identical to that in Experiment 1. During Session 2, the only difference was that both houselight and tone were continuously off. That is, all contingencies of reinforcement were identical in Session 2 to those in Sessions 1 and 3, except for the absence of external discriminative stimuli; reinforcement in vary continued to depend on low-frequency sequences, and reinforcement in yoke was provided probabilistically. Technically, Session 2 presented a mixed schedule, or the analogue of a multiple schedule but without external cues.

\section{Results}

Figure 4 shows that when external stimuli were present, $U$ values in vary and yoke components differed, as in Experiment 1 , but that these values were essentially identical when the external stimuli were absent during Session 2. Initial and later trials were combined for purposes of statistical analyses because there were too few trials for sep-

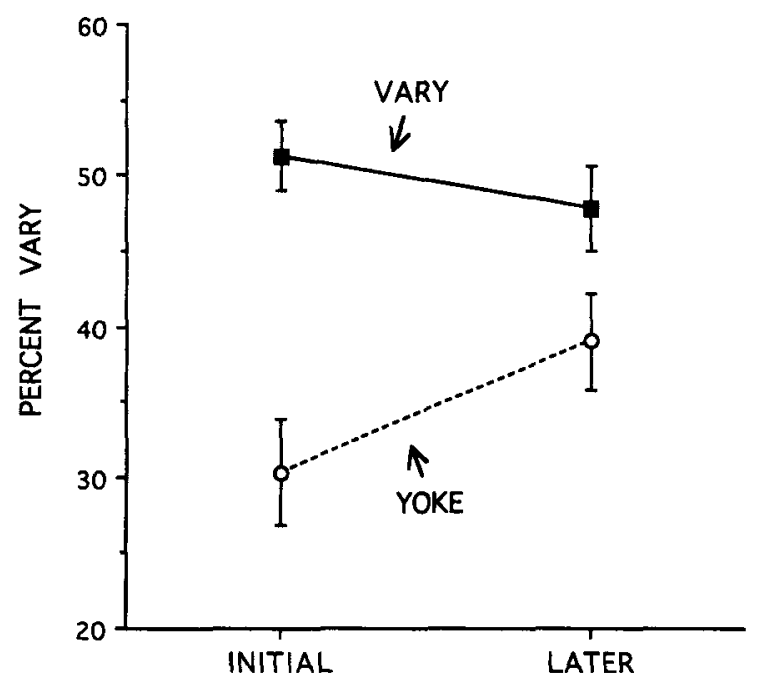

Figure 3. Average percentage of trials that met the variability contingencies, or percent vary, under vary and yoke stimulus conditions in Experiment 1, divided into initial trials and later trials. Averages across the 20 rats represent the final 300 responses in each condition. Error bars show standard deviations. 


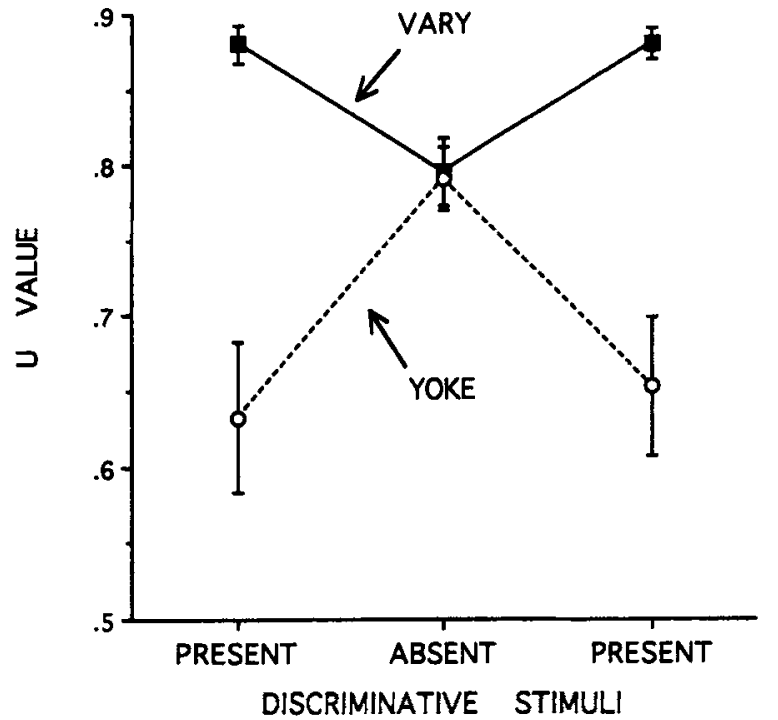

Figure 4. Average $U$ values during each of the three sessions in Experiment 2, shown separately for vary and yoke components. During the present sessions, discriminative stimuli indicated vary versus yoke. During the absent session, no discriminative stimuli were provided. Averages are across the 20 rats in the experiment. Error bars show standard deviations.

arate analyses. There was a significant contingency (vary vs. yoke) by session (stimuli-present, stimuli-absent, stimulipresent) interaction $[F(2,36)=22.36, p<.0001]$ and simple-effects analyses showed that vary versus yoke differed in the two stimuli-present sessions $[F(1,18)=27.32$ and 26.74 , respectively, $p<.001$ ], but that $U$ values did not differ during the intervening stimuli-absent session $[F(1,18)=.248$, n.s. $]$.

Similar results are shown by the percent vary statistic in Figure 5 . The contingency $\times$ session interaction was statistically significant $[F(2,36)=21.10, p<.0001]$, the differences between vary-component and yoke-component variability were significant during the two sessions in which stimuli were present $[F(1,18)=25.15$ and 40.03 , respectively, $p<.001]$, but variability was the same in the two components when the external stimuli were absent $[F(1,18)=.200$, n.s. $]$.

\section{DISCUSSION}

These experiments clearly demonstrate discriminative stimulus control over sequence variability in rats. When reinforcement depended on high variability under one stimulus, sequence variability was significantly higher than it was when reinforcement was independent of variability under a second stimulus. The difference was greatest at the beginning of the vary and yoke components, before the consequences of responding could provide additional information concerning the operative schedule. If the first sequence in a component did not result in reinforcement, levels of variability converged - that is, variability decreased in the vary component and increased in yoke. This convergence was opposite to the effect that would be predicted if subjects were using reinforcement itself as a cue to distinguish one component from the other. Further support for stimulus control was seen in Experiment 2, where removing the discriminative stimuli caused the differences in variability to disappear.

Some rats showed differences in the vary and yoke stimuli only after many sessions, and, for some, the final difference in variability was small. These results may be related to the particular reinforcement contingencies used, particularly the yoke contingencies. The logic of the experiment required that infrequently occurring sequences would be reinforced in the presence of one stimulus, whereas any response sequence would be reinforced probabilistically in the presence of the second stimulus. Of course, reinforcing any behavior in yoke permitted the animals to respond with high variability, which is what happened in some cases. For some of the animals, levels of variability in yoke decreased only with extended experience.

As noted in the introduction, previous research in our laboratory showed that some rats continued to respond differentially following training under a vary-yoke multiple schedule, despite the removal of external cues. In the previous research, components of the multiple schedule were of fixed and long duration, thereby permitting differential responding based on feedback from the schedules themselves. Such feedback-based differential responding was not possible under the present procedure, and it is therefore likely that both exteroceptive and endogenous

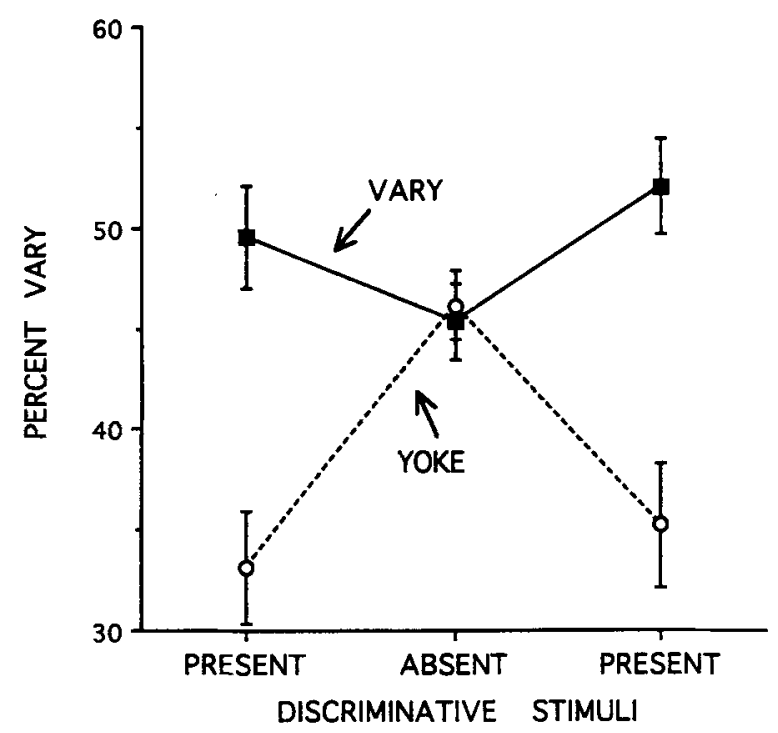

Figure 5. Average percentage of trials that met the variability contingencies in each of the three sessions of Experiment 2, shown separately for vary and yoke components. During the present sessions, discriminative stimuli indicated vary versus yoke. During the absent session, no discriminative stimuli were provided. Averages are across the $\mathbf{2 0}$ rats in the experiment. Error bars show standard deviations. 
stimuli may serve as cues for variable behaviors, depending on which of these is predictive of reinforcement.

The reinforcement-of-variability procedure used in the present experiments was similar to procedures developed by Blough (1966) and Shimp (1967). Blough reinforced pigeons' "least frequent" interresponse times (IRTs). Sixteen "bins" were created such that a random-in-time generator would be expected to fill all bins equally. Pigeons' responses were reinforced if the IRT entered that 1 of the 16 bins whose frequency was (at the moment) least frequent. In an analogous procedure, Shimp reinforced choices across two keys only if the pigeon emitted a sequence (defined by the last four responses) which was least frequent. Blough's pigeons demonstrated highly variable IRTs and Shimp's pigeons highly variable choices. The present procedure used a discrete-trials procedure - four consecutive responses terminated with either timeout or food-because most recent studies of behavioral variability have employed similar discrete sets of responses (see, e.g., Machado, 1989; Page \& Neuringer, 1985; Schwartz, 1988). A second difference in procedures was that, in Blough and Shimp, only the single least frequent instance could be reinforced, whereas the threshold contingencies of the current experiments were more permissive, with reinforcement at a particular time in the experiment possible for as many as 11 of the 16 possible sequences. The permissive nature of the contingencies may have been responsible for the intermediate levels of variability generated. In the vary component of Experiment 1, for example, the rats' average $U$ value was .879 , whereas, for comparison, a simulated random generator under the same contingencies yielded a $U$ value of .990 . Similarly, the average of the rats' percentage vary during the vary component was $49.6 \%$, whereas a simulated random generator met the variability contingencies $79.1 \%$. Also contributing to obtained levels of variability during the vary component may have been induction from the yoke component, during which repeated sequences could be reinforced.

Under the least-frequent procedures of Blough and Shimp, as well as in the current threshold procedure, reinforcement depended directly on evenness of sequence distributions and only indirectly on sequence repetitionsif a sequence was often repeated, distributions could not be even. In some previous methods, such as the lag procedure, reinforcement depended on the absence of repetitions and indirectly on evenness of distributions (Machado, 1989; Page \& Neuringer, 1985; Schwartz, 1988). The relative importance of no repetitions and even distributions can be manipulated under the threshold procedure by varying the value of the weighting coefficient, $w$. If $w=$ 1.0 , variability is evaluated strictly on the basis of the long-term flatness of the distribution. If $w$ is set to very low values, variability is judged mainly on the basis of recent repetitions. Intermediate values of $w$ take both longterm distribution and short-term repetition into account.

Discriminative stimulus control over variability is relevant to a number of issues concerning operant behavior generally. We will discuss five of these. First, as indicated in the introduction, the operant is characterized by a threeterm contingency. Since Skinner (1935), the R term, or "response," has been understood to be a class of responses, not an instance. Thus, for example, when discriminative stimulus control is established over leverpressing, any effective way to depress the lever is included in $R$, and, in actuality, rats often press the lever in different ways, sometimes pressing with one paw and other times with the other (Stokes \& Balsam, 1991). The current work suggests that within-class distributions can be modified by consequences, much in the same way that between-class distributions can be modified. This view can be summarized as follows:

$$
\mathrm{S}_{\mathrm{C}, \mathrm{V}}^{\mathrm{D}} \rightarrow \mathrm{R}_{\mathrm{C}, \mathrm{V}} \rightarrow \mathrm{S}^{\mathrm{R}} \text {, }
$$

where $\mathrm{C}$ defines the class of instances and $\mathrm{V}$ defines the level of variation among the instances. The use of $\mathrm{C}$ and $\mathrm{V}$ as subscripts implies that a particular discriminative stimulus could indicate both response class and level of variation within the class; or separate and possibly orthogonal stimuli may indicate class and level of variations. In many cases, there are no externally imposed requirements regarding the level of variation, although an uneven response distribution may result from differences among instances-for example, responses using minimal force or otherwise requiring minimal effort may be most probable. In other cases, there are stringent requirements for a highly repetitive performance-for example, when a particular force is required or particular interresponse time, or when a single correct response is required in an educational setting. In yet other cases, high levels of variability are differentially reinforced-for example, in certain game situations or as part of creative activities or problem solving.

Second, according to a number of influential theories, operant responses are selected from a substrate of variable behaviors (Machado, 1992, 1993; Palmer \& Donahoe, 1992; Skinner, 1981; Staddon \& Simmelhag, 1971; Stokes, 1995). It is increasingly clear that variation itself is selected by consequences. Therefore reinforcement-of-variability effects should be considered when formulating models of operant behavior and, in particular, dynamic models (see, e.g., Commons, Grossberg, \& Staddon, 1991; Donahoe \& Palmer, 1994; Reid \& Staddon, in press).

We do not yet know the mechanism governing the variability of instances within a response set (but see Machado, 1997). Does instrumental variability result from deterministic, chaotic, or stochastic processes (Sachs, 1988; Schoffeniels, 1976; Stewart, 1989)? Possibly the $S_{V}^{D}$ governs the size of a class or, alternatively, the distribution of probabilities of the active instances within a class. Whatever the underlying mechanism, theories of operant behavior must account not only for stimulus control over response classes, but also for control over the distribution of instances within the class, or variability.

Third, although operant behavior is often referred to as "voluntary," there has been little attempt to explain the term (see, however, Skinner, 1953, pp. 110-116). Stimulus 
control over operant variability might provide some explanation, because one characteristic of voluntary behavior is manifestation of high predictability when predictability is functional - stopping at the red traffic light—and of high variability when unpredictability is functional--attempting to elude an enemy or predator. A related characteristic of voluntary behavior is that it is potentially unpredictable while, at the same time, being potentially explainable. Identification of stimulus-controlled variability helps to explain highly unpredictable responding. Although all physical systems show variability at some level of analysis (Peirce, 1923), it may be only voluntary behavior that exhibits operantly controlled variability.

Fourth, the consideration of variability as being reinforced and under stimulus control could motivate a reconsideration of basic assumptions. The goal of many behavioral scientists has been to predict and control behavior (Zuriff, 1985), but levels of prediction and precision of control will depend on the particular contingencies, implicit and explicit, concerning within- and between-class variability. Stated differently, even when the class is predicted and controlled, within-class instances may be more or less predictable, depending on the contingencies that relate consequences to variability. In the extreme, the class of all possible operant behaviors may be specified by stimuli and contingencies. Thus, a request to "behave unpredictably" may cause high levels of variation among members of the class of "all currently possible operant behaviors." Uncertainty of prediction by any observer, possibly including the responder himself or herself, could be extremely high.

Fifth, operant variability may help to explain developmental changes in learning (Neuringer \& Huntley, 1992; Siegler, 1994, 1996) and learning difficulties. One source of learning difficulty may be a substrate variability that is abnormally high - as, for example, has been hypothesized for individuals diagnosed with attention deficit/hyperactivity disorder (Mook, Jeffrey, \& Neuringer, 1993; however, see Saldana \& Neuringer, in press). The opposite may be true for individuals diagnosed with autism, where abnormally low levels of variability could be characteristic (Boucher, 1977; Miller, 1996). Thus, differences in baseline variability and differences in sensitivity of variability to consequences may help to characterize the development of different cognitive and behavioral competencies and disorders.

\section{REFERENCES}

Boucher, J. (1977). Alternation and sequencing behavior, and response to novelty in autistic children. Journal of Child Psychology \& Psychiatry, 18, 67-72.

BLOUGH, D. S. (1966). The reinforcement of least frequent interresponse times. Journal of the Experimental Analysis of Behavior, 9, 581-591.

Bryant, D., \& Church, R. M. (1974). The determinants of random choice. Animal Learning \& Behavior, 2, 245-248.

Cohen, L., Neuringer, A., \& Rhodes, D. (1990). Effects of ethanol on reinforced variations and repetitions by rats under a multiple schedule. Journal of the Experimental Analysis of Behavior, 54, 1-12.

Commons, M. L., Grossberg, S., \& Staddon, J. E. R. (1991) Neural network models of conditioning and action. Hillsdale, NJ: Erlbaum. DEVENPORT, L. D. (1983). Spontaneous behavior: Inferences from neuro- science. In R. Mellgren (Ed.), Animal cognition and behavior (pp. 83125). Amsterdam: North-Holland.

Donahoe, J. W., \& Palmer, D. C. (1994). Learning and complex behavior. Boston: Allyn \& Bacon.

Holman, J., Goetz, E. M., \& BaER, D. M. (1977). The training of creativity as an operant and an examination of its generalization characteristics. In B. Etzel, J. LeBland, \& D. Baer (Eds.), New development in behavior research: Theory, method and application (pp. 441-47I). Hillsdale, NJ: Erlbaum.

JENKINS, H. M. (1965). Measurement of stimulus control during discriminative operant conditioning. Psychological Bulletin, 64, 365. 376.

MACHADO, A. (1989). Operant conditioning of behavioral variability using a percentile reinforcement schedule. Journal of the Experimental Analysis of Behavior, 52, 155-166.

MACHADO, A. (1992). Behavioral variability and frequency-dependent selection. Journal of the Experimental Analysis of Behavior, 58, 241-263.

MACHADO, A. (1993). Learning variable and stereotypical sequences of responses: Some data and a new model. Behavioural Processes, 30. 103-130.

MACHADO, A. (1997). Increasing the variability of response sequences in pigeons by adjusting the frequency of switching between two keys. Journal of the Experimental Analysis of Behavior, 68, i-25.

Manabe, K., Staddon, J. E. R., \& Cleaveland, J. M. (1997). Control of vocal repertoire by reward in budgerigars (Melopsittacus undulatus). Journal of Comparative Psychology, 111, 50-62

MiLler, N. (1996). Autism and reinforced variability. Unpublished undergraduate thesis, Reed College.

MOOK, D. M., JefFreY, J., \& NeURinger, A. (1993). Spontaneously hypertensive rats (SHR) readily learn to vary but not repeat instrumental responses. Behavioral \& Neural Biology, 59, 126-135.

Morgan, L., \& Neuringer, A. (1990). Behavioral variability as a function of response topography and reinforcement contingency. Animal Learning \& Behavior, 18, 257-263.

NeURINGEr, A. (1992), Choosing to vary and repeat. Psychological Science, 4, 246-250.

Neuringer, A., \& Huntley, R. W. (1992). Reinforced variability in rats: Effects of gender, age and contingency. Physiology \& Behavior, 51, 145-149.

PAGE, S., \& NeURINGer, A. (1985). Variability is an operant. Journal of Experimental Psychology: Animal Behavior Processes, 11, 429-452.

Palmer, D. C., \& Donahoe, J. W. (1992). Essentialism and selectionism in cognitive science and behavior analysis. American Psychologist, 47, 1344-1358.

Peirce, C. S. (1923). Chance, love, and logic. New York: Barnes \& Noble. PrYOR, K. W., HAAG, R., \& O'REILly, J. (1969). The creative porpoise: Training for novel behavior. Journal of the Experimental Analysis of Behavior, 12, 653-661.

REID, A. K., \& STADDON, J. E. R. (in press). A dynamic route-finder for the cognitive map. Psychological Review.

SaChs, M. (1988). Einstein versus Bohr. La Salle, IL: Open Court.

Saldana, R. L., \& Neuringer, A. (in press). Is instrumental varjabitity abnormally high in children exhibiting ADHD and aggressive behavior? Behavioural Brain Research.

SChoffeniels, E. (1976). Anti-chance (B. L. Reids, Trans.). New York: Pergamon.

SCHWARTZ, B. (1982a). Failure to produce response variability with reinforcement. Journal of the Experimental Analysis of Behavior, 37, 171-181.

ScHWARTZ, B. (1982b). Reinforcement-induced stereotypy: How not to teach people to discover rules. Journal of Experimental Psychology: General, 111, 23-59.

SchwarTZ, B. (1988). The experimental synthesis of behavior: Reinforcement, behavioral stereotypy and problem solving. In G. H. Bower (Ed.), The psychology of learning and motivation (Vol. 22, pp. 93135). New York: Academic Press.

ShImP, C. P. (1967). Reinforcement of least-frequent sequences of choices. Journal of the Experimental Analysis of Behavior, 10, 57-65.

SIEGLER, R. S. (1994). Cognitive variability: A key to understanding cognitive development. Current Directions in Psychological Science, $1,1-5$. 
SIEGLER, R. S. (1996). Emerging minds: The process of change in children 's thinking. New York: Oxford University Press.

SKINNER, B. F. (1935). The generic nature of the concepts of stimulus and response. Journal of General Psychology, 12, 40-65.

SKINNER, B. F. (1953). Science and human behavior. New York: Macmillan.

Skinner, B. F. (1981). Selection by consequences. Science, 213, 501-504.

Staddon, J. E. R., \& Frank, J. (1974). Mechanisms of discrimination reversal in pigeons. Animal Behaviour, 22, 802-828.

Staddon, J. E. R., \& Simmelhag, V. L. (1971). The "superstition" experiment: A reexamination of its implications for the principles of adaptive behavior. Psychological Review, 78, 3-43.
STEWART, I. (1989). Does God play dice: The mathematics of chaos. Cambridge, MA: Basil Blackwell.

STOKES, P. D. (1995). Learned variability. Animal Learning \& Behavior, 23, 164-176.

StoKes, P. D., \& Balsam, P. D. (1991). Effects of reinforcing preselected approximations on the topography of the rat's bar press. Journal of the Experimental Analysis of Behavior, 55, 213-231.

ZURIFF, G. E. (1985). Behaviorism: A conceptual reconstruction. New York: Columbia University Press.

(Manuscript received April 14, 1997;

revision accepted for publication September 5, 1997.) 